\title{
ENDURECIMENTO DO AÇO AISI 1140 POR TÊMPERA*
}

\author{
Géssica Padilha de Souza ${ }^{1}$ \\ Adielson Rafael Oliveira Marinho ${ }^{2}$ \\ João Henrique Assunção Vieira ${ }^{3}$ \\ Torben Ulisses da Silva Carvalho 4 \\ Carlos Vinicius de Paes Santos ${ }^{5}$
}

\section{Resumo}

Nos dias atuais, tem-se uma busca incessante por materiais que atendam às solicitações de trabalho exigidas, mas que possuam um baixo custo de fabricação. Diante disso, esse trabalho tem por objetivo o endurecimento do aço AISI 1140, que foi normalizado, temperado com resfriamento em salmoura e seguido de revenimento, com posterior caracterização metalográfica e ensaio de dureza HRC. Através desses tratamentos, foi possível aumentar significativamente a dureza do aço em questão, além das modificações nas fases da microestrutura e consequentemente, de suas propriedades.

Palavras-chave: Aço AISI 1140; Têmpera; Endurecimento.

\section{Abstract}

\section{HARDENING OF THE AISI 1140 STELL BY QUENCHING}

Nowadays, there is a constant search for materials that meet the required work requests, but with a low manufacturing cost. Therefore, this study aims to hardening of AISI 1140 steel, which was normalized, hardened with cooling in brine and followed by tempering, with further characterization metallographic and HRC hardness testing. By these treatments, it was possible the significantly hardness increase of the steel in question, in addition to changes in the phases of the microstructure and hence its properties.

Keywords: AISI 1140 Steel; Quenching; Hardening.

1 Graduando em Engenharia de Materiais, Estudante, Faculdade de Engenharia de Materiais, Universidade Federal do Sul e Sudeste do Pará, Marabá, Pará, Brasil.

2 Graduando em Engenharia de Materiais, Estudante, Faculdade de Engenharia de Materiais, Universidade Federal do Sul e Sudeste do Pará, Marabá, Pará, Brasil.

3 Graduando em Engenharia de Materiais, Estudante, Faculdade de Engenharia de Materiais, Universidade Federal do Sul e Sudeste do Pará, Marabá, Pará, Brasil.

4 Graduando em Engenharia de Materiais, Estudante, Faculdade de Engenharia de Materiais, Universidade Federal do Sul e Sudeste do Pará, Marabá, Pará, Brasil.

5 Graduado em Engenharia de Materiais, Bacharel, Faculdade de Engenharia de Materiais, Universidade Federal do Sul e Sudeste do Pará, Marabá, Pará, Brasil. 


\section{INTRODUÇÃO}

Há milhares de anos com a descoberta do aço, a humanidade aprendeu que com aquecimento e resfriamento dos aços, ou trabalhando com aços de teores de carbono mais elevados, poderia modificar suas propriedades mecânicas e metalúrgicas, tornando-os mais duros, trabalháveis, dúcteis, resistentes, frágeis, dentre outras características [1]

O tratamento térmico é o processo de aquecimento e resfriamento, em condições controladas de ligas metálicas, ferrosas e não ferrosas, onde se objetiva modificar as suas propriedades. Dessa forma obtém-se uma variedade de propriedades que permitem que as ligas sejam adequadas a diversas aplicações, conseguindo-se tais efeitos com reduzidos gastos financeiros. [1]

Dentre os tratamentos térmicos aplicados aos aços tem-se a têmpera e o revenimento, cujo objetivo fundamental é obter uma estrutura martensítica, o que exige um aquecimento acima de sua zona crítica durante o tempo necessário, seguido de resfriamento rápido em um meio como o óleo, água ou salmoura, propiciando ao aço aumento na sua dureza e na sua resistência a tração. $O$ revenimento tem por finalidade aliviar ou eliminar tensões internas geradas pela têmpera, conferindo ao aço aumento na ductilidade e resistência ao choque térmico [2].

O aço carbono AISI 1140 é um aço de corte rápido que possui uma resistência elevada, e é combinado com enxofre a fim de aumentar a sua usinabilidade característica. Por conta dessa característica, esse tipo de aço é denominado de "corte fácil". A melhoria da usinabilidade confere velocidade e produtividade aos processos industriais com esse tipo de aço [3].

Por se tratar de um aço médio carbono, o aumento da dureza por têmpera nesse tipo de aço é viável e, dessa forma, esse trabalho objetiva o endurecimento do aço AISI 1140, por meio dos tratamentos térmicos de têmpera e revenido. Tal endurecimento foi comprovado por ensaio de dureza. A microscopia óptica foi aplicada para visualização da formação de fases e microconstituintes, antes e após os tratamentos térmicos.

\section{MATERIAIS E MÉTODOS}

\subsection{Metodologia dos Tratamentos Térmicos}

Os corpos de prova (CP's) do aço AISI 1140 foram normalizados à uma temperatura de $860^{\circ} \mathrm{C}$ [4] por uma hora, sendo o tempo suficiente para a geometria e espessura da peça, seguindo com um resfriamento ao ar estático. Após o resfriamento os CP's foram preparados para a caracterização metalográfica, seguindo com o ensaio de dureza nos mesmos.

Em seguida, foi realizada a têmpera nos CP's onde estes foram aquecidos a $830^{\circ} \mathrm{C}$ [3], mantidos por uma hora, sendo estes resfriados rapidamente em salmoura. Posteriormente, foram para a caracterização metalográfica e para o ensaio de dureza.

O revenimento dos CP's do aço 1140 foi feito a $350^{\circ} \mathrm{C}$ [3] por uma hora seguindo com resfriamento moderado ao ar estático [5]. Os CP's foram para a caracterização metalográfica e para o ensaio de dureza. A Figura 1 mostra esquematicamente os tratamentos térmicos realizados no aço AISI 1140. 


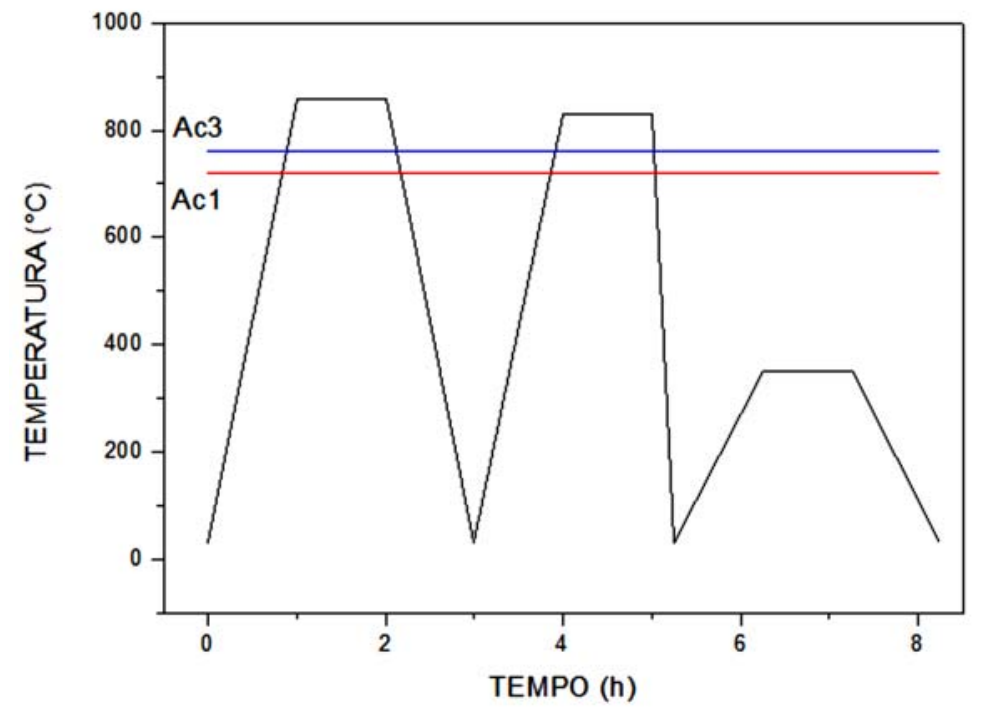

Figura 1. Esquema dos tratamentos térmicos realizados no aço AISI 1140.

\subsection{Caracterização Metalográfica}

A caracterização metalográfica realizada foi a micrográfica. Os CP's do aço AISI 1140, depois do tratamento térmico, foram lixados na sequência de lixas: 80,100 , $220,320,400,600,1200,1500$ e polidos com pasta de diamante (6, 3 e $1 \mu \mathrm{m})$. Os CP's polidos foram atacados com Nital $3 \%$, para visualização da microestrutura em microscópio ótico. De cada tratamento foi retirado uma amostra que foi lixada somente até a malha 600, para realização do ensaio de dureza Rockwell C, HRC.

\section{RESULTADOS E DISCUSSÃO}

Com base nos resultados do ensaio de dureza do aço AISI 1140 mediante os tratamentos térmicos realizados, disposto na Tabela 1, percebe-se um aumento significativo na dureza.

Tabela 1. Resultados do ensaio de dureza do aço AISI 1140

\begin{tabular}{cccc}
\hline & NORMALIZADO & TEMPERADO & REVENIDO \\
\hline Dureza HRC & 9,5 & 55 & 48 \\
\hline Desvio Padrão & 0,8 & 2,7 & 1,3 \\
\hline
\end{tabular}

A partir desses resultados do ensaio de dureza, percebe-se que a normalização foi satisfatória, já que esta apresentou uma dureza na faixa do aço em questão ((7) a 21 HRC) [6], significando que ocorreu a remoção de qualquer tratamento que este aço tenha sofrido anteriormente. Observando o resultado da dureza do aço temperado, verifica-se o aumento significativo do valor de dureza do aço normalizado, mostrando que o tratamento foi eficiente, além deste ter apresentado a dureza próxima da martensita. Através da Figura 2, utilizando a quantidade de carbono do aço e a dureza alcançada, pode-se estimar que se tenha em torno de $97 \%$ de fase martensita formada no tratamento de têmpera do aço AISI 1140. 


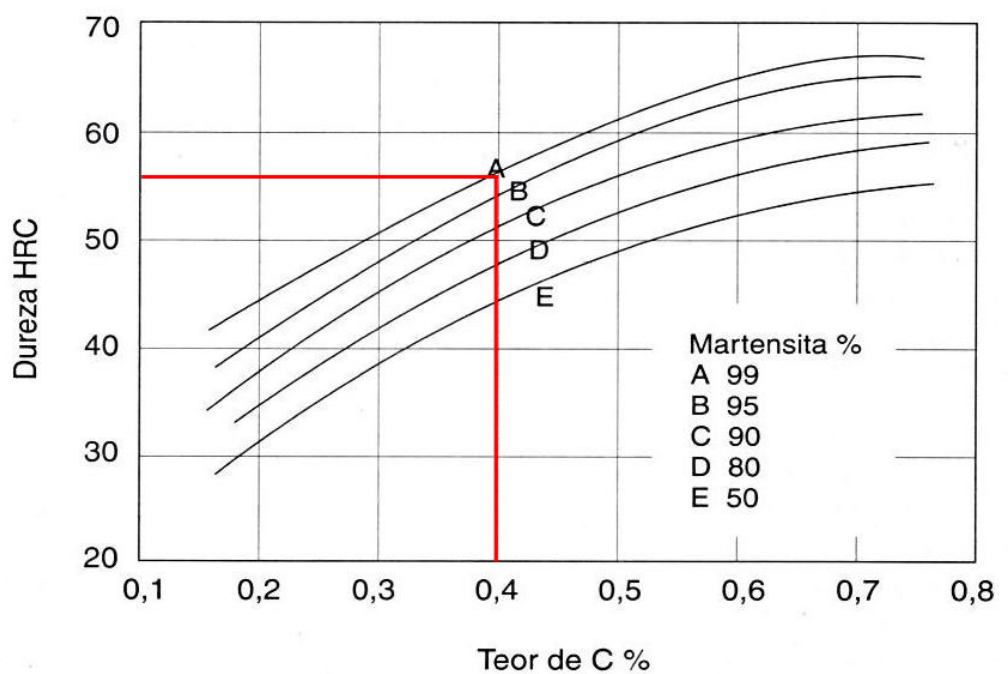

Figura 2. Relação entre dureza, teor de carbono e quantidade de martensita.

Analisando o tratamento térmico de revenimento, verifica-se o decréscimo de dureza, o que já era esperado, uma vez que o revenido alivia as tensões resultantes da têmpera, aumentando a ductilidade. A Figura 3 dispõe as caracterizações microestruturais do aço AISI 1140 normalizado, temperado e revenido.
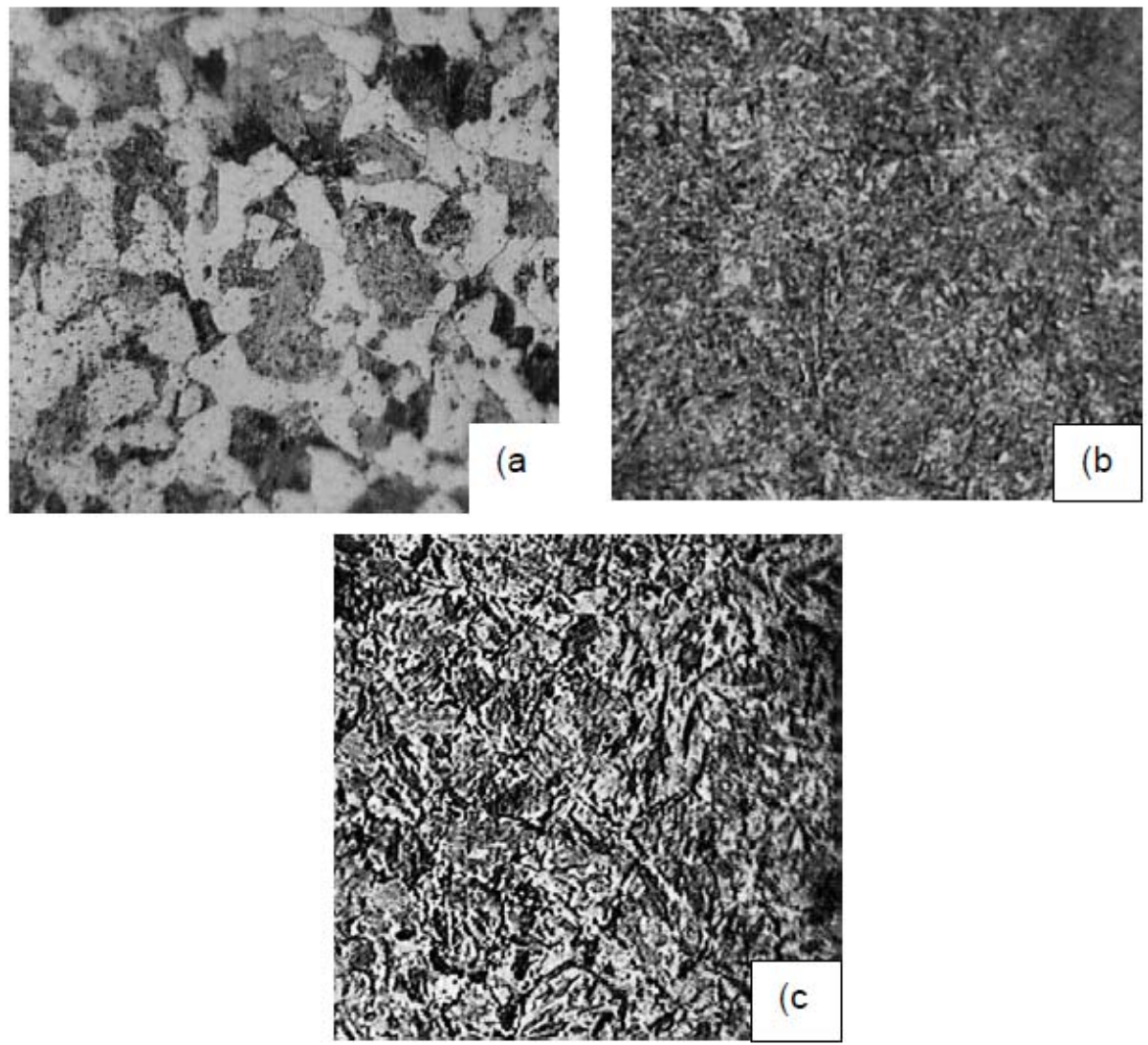

Figura 3. Microestruturas do aço AISI 1140 com aumento de 1500x: (a) normalizado, (b) temperado e (c) revenido.

A microestrutura normalizada (Figura 3a) apresenta as fases perlita e ferrita. A ferrita é constituinte por uma solução sólida de inserção de carbono em ferro alfa. É o constituinte mais dúctil dos aços, porém é o mais tenaz em aços carbono-manganês 
e o mais maleável. Sua resistência à tração é de $27,46 \mathrm{kgf} / \mathrm{mm}^{2}$ e sua solubilidade máxima é de $0,008 \%$. Pode também manter em solução de substituição a outros elementos tais como $\mathrm{Si}, \mathrm{P}, \mathrm{Ni}, \mathrm{Cr}, \mathrm{Cu}$, que aparecem nos aços, bem como impurezas ou como elementos de ligação.

A perlita é formada por uma mistura eutetóide de duas fases, ferrita e cementita, sua estrutura está constituída por lâminas alternadas de ferrita e cementita, sendo a espessura das lâminas de ferrita superior ao das de cementita, estas últimas ficam em relevo depois do ataque com ácido nítrico.

A perlita é mais dura e resistente que a ferrita, porém mais branda e maleável que a cementita. Apresenta-se em forma laminar, reticular e globular. A microestrutura temperada (Figura 3b) apresentou a fase martensita que é uma solução sólida, intersticial e supersaturada de carbono em ferro alfa. Apresenta-se na forma de agulhas cruzadas. Os átomos de ferro estão como na ferrita, nos vértices. Os átomos de carbono estão nas faces e nas arestas, apresentando, por isso, uma rede distorcida. Esta distorção da rede, que é a responsável pela dureza da martensita, apresenta uma rede tetragonal. Suas características mecânicas são resistência a tração entre 170-250 kgf/ $/ \mathrm{mm}^{2}$, dureza HRC entre 50-60, além de ser magnética.

A microscopia do revenido (Figura 3c) apresentou a fase sorbita. Ao realizar o aquecimento, a martensita experimenta uma série de transformações e no intervalo compreendido entre 400 e $650^{\circ} \mathrm{C}$, a antiga martensita perdeu tanto carbono, que se converteu em ferrita dando origem a sorbita, que é uma fase constituída por lamelas muito finas de carbetos de ferro, dispostas entre camadas muito finas de ferro. A sorbita é quase tão dura quanto à martensita, mas muito menos frágil [7].

\section{CONCLUSÃO}

Os tratamentos térmicos possibilitam transformações de fase no estado solido nos aços, que são de suma importância para os materiais, uma vez que através destes podem-se alterar suas propriedades como: dureza, resistência mecânica, resistência ao choque térmico e alongamento, através do aquecimento e do resfriamento, visando a modificação da microestrutura dos aços, conferindo uma maior aplicação tecnológica.

Por meio do tratamento térmico de têmpera em salmoura e revenido foi possível aumentar significativamente a dureza do aço AISI 1140, além das modificações nas fases da microestrutura e logo de suas propriedades.

\section{REFERÊNCIAS}

1 Vale ARM. Tratamento Térmico. Belém: IFPA, 2011. [acesso em 18 dez. 2014].

Disponível em:

http://redeetec.mec.gov.br/images/stories/pdf/eixo_ctrl_proc_indust/tec_metal/trat_termi co/161012_trat_term.pdf..

2 Chiaverini $\bar{V}$. Tecnologia Mecânica. São Paulo: McGraw-Hill, 1986.

3 Azo Materials. AISI 1140 Carbon Steel (UNS G11400). [acesso em 15 nov. 2014].

Disponível em: http://www.azom.com/article.aspx?ArticlelD=6593

4 Chiaverini V. Aços e ferros fundidos. São Paulo: ABM, 2012.

5 Yoshida A. Metais, Ligas e Tratamentos Térmicos. Rio de Janeiro: Esparsa LDA, 1999.

6 Gerdau. Manual de Aços. São Paulo: Gerdau, 2003.

7 Colpaert H., Metalografia dos Produtos Siderúrgicos Comuns. São Paulo: Edgard Blucher, 1974 